\title{
COMPARATIVE ASSESSMENT OF DISPOSABLE PLATES FROM THE USER AND POLICY PERSPECTIVE
}

\author{
Soumya Jain \\ Research Associate \\ Department of Energy Science and Engineering (DESE), IIT Bombay \\ Mumbai, Maharashtra, India \\ E-mail: soumya.jain21@gmail.com \\ Prof. Anand B. Rao \\ Associate Professor \\ Centre for Technology Alternatives for Rural Areas (CTARA), IIT Bombay \\ Mumbai, Maharashtra, India \\ E-mail: a.b.rao@iitb.ac.in
}

\begin{abstract}
Disposable plates are used for serving food because of their easy handling and disposal. Traditionally, disposable plates made of leaves were used in India. Different types of plant leaves have been used for plate making in different states. The present market of disposable plates, however, largely comprises of paper and expanded polystyrene (foam) plates.

The three types of leaf plates studied are Areca (Areca catechu), Siali (Bauhinia vahlii) and Sal (Shorea robusta). More than half of the production cost of leaf plates is attributed to procurement of raw material and labour wages. This indicates that leaf plate making is a labour intensive business creating employment in rural areas. Areca plates (Rs 7/ plate) have the highest market price while paper plates (Rs $0.5 /$ plate) have the lowest. It was found that the energy consumption of making Sal and Siali plates is comparable to that of making the paper plates; while the energy consumption of making Areca leaf plates is the highest. Nowadays, Sal and Siali plates have an embedded polythene sheet. Thus, looking at the currently available designs in the market, non-coated paper plates and Areca leaf plates were found to be the only completely biodegradable disposable plates.

The present paper attempts to compare three major types of leaf plates with paper plates on the basis of a variety of attributes such as economic, performance and environmental from the user perspective and the policy perspective using Analytic Hierarchy Process (AHP). The attribute data was collected through key informant interviews and secondary sources. The user perspective gives the user a decision making template to select from the biodegradable disposable plates available in the market. Similarly, the policy perspective can help the policy maker in decision making or formulating policies which promote sustainable development.


IJAHP: International Symposium of the Analytic Hierarchy Process 2014, Washington D.C., U.S.A.

Keywords: Disposable plates, leaf plates, comparative assessment, AHP 